\title{
Fuzzy Logic Based Maximum Power Point Tracking Using Boost Converter for Solar Photovoltaic System in Kuwait
}

\author{
Mohamed A. El-Sayed ${ }^{1}$ and Steven Leeb ${ }^{2}$ \\ ${ }^{1}$ Department of Electrical Engineering \\ College of Engineering and Petroleum, Kuwait University (Kuwait) \\ Phone: +965 249-83347, e-mail: elsmah@hotmail.com \\ ${ }^{2}$ Department of Electrical and Computer Engineering \\ MIT, Cambridge, MA 02139-4307(USA) \\ Phone: +1 617-253-9360, email: sbleeb@ mit.edu
}

\begin{abstract}
Currently, the production of the rapid increasing electrical energy in Kuwait depends mainly on oil and its derivatives, which result in environmental pollution. Moreover, the export of oil production represents a key income for Kuwait and any saving in its consumption represents an essential concern to land's economy. Therefore, the power utility and economy of Kuwait will benefit from substituting fossil fuels by clean and renewable energy resources such as solar energy.

For efficient utilization of solar energy, the PV panel should track the maximum power point (MPP) under various weather conditions in Kuwait. Most of existing MPP tracking techniques depend mainly on perturb \& observe $(\mathrm{P} \& \mathrm{O})$ or incremental conductance (IC) algorithm using conventional PID controllers. On the other side, fuzzy logic controller (FLC) provides an adaptive nature, fast response, good performance and ability to handle non-linear characteristics. In this paper, the proposed (FLC) substitutes PID controller in P\&O and IC (MPPT) under different weather conditions in Kuwait. The obtained results of the proposed (FLC) are compared with conventional PID controller. The performance of the implemented PV panel is validated and the results indicated that FLC has successfully tracked the MPP with minimum voltage oscillations.
\end{abstract}

Key words: MPPT, Fuzzy logic control, DC-DC boost converters, PV panels, PWM.

\section{Introduction}

The Ministry of electricity and water in Kuwait (MEW) has estimated that, with the peak load increasing by $6-8 \%$ per year, an additional 10,000 MW of installed electrical generating capacity will be necessary by year 2020 [1]. The primary energy source for the existing thermal power stations of Kuwait depends mainly on natural gas and liquid oil products. These power plants are main source of harmful gas emission. Therefore, the country plans to generate $10 \%$ of its electricity from renewable energy resources by 2020. In this respect, MEW has taken more direct actions to install PV panels to supply electricity to the building of its headquarters.
The knowledge of the solar radiation and temperature data is essential for design and sizing of the PV system $[2,3]$. The temperature variations in Kuwait averaged for each day over 6 years of recorded data are shown in Fig 1. Similarly, Fig. 2 displays the average daily solar radiation (SR) on a horizontal surface in Kuwait recorded for the same period. Fig. 2 proves that Kuwait has an abundance of solar energy potential. Thereby, the monthly averaged solar intensity on horizontal surface area is $3.26 \mathrm{kWh} / \mathrm{m}^{2}$ in December and $8.16 \mathrm{kWh} / \mathrm{m}^{2}$ in June. The annual average value of solar radiation reaches $5.9 \mathrm{kWh} / \mathrm{m}^{2}$. On the other side the electrical load in Kuwait is high in summer due to air conditioning and low load in winter depending on temperatures and relative humidity variations. This shows that the peak load matches the maximum incident solar radiation and then its electricity generation would results in very promising and efficient participation of solar energy in supplying electrical demand in Kuwait.

Recently, there is an increasing interest in installing gridconnected PV systems to form distributed generation. This trend is attributed to economic and technical benefits of distributed generation in micro-grids. On the other hand, the dispersed grid-connected PV systems require efficient power conditioning converters. The power conditioning devices include DC/DC boost converter and voltage source inverter. Many controlling strategies have been developed [4-6] to control the power conditioning converters. In most PV systems, MPPT algorithms are utilized for full extraction of the available solar energy. The controller adopts the pulse width modulation (PWM) technique to determine the converter duty cycles to obtain stable MPP of the PV array under the environmental condition in Kuwait.

Until now different MPPT algorithms are studied [4-9] using conventional PID controller to adjust the duty cycle of the DC/DC boost converter. FLC has been implemented on real-time control system and results in 
good performance even for nonlinear and time-varying system [7-9]. Due to its simplicity and easy to implement, this paper developed FLC based on P\&O and IC algorithms for obtaining the maximum power output of photovoltaic array under different weather conditions in Kuwait. The paper is organized as follows: Section 2 describes the grid connected PV system while section 3 presents the MPPT algorithm. Section 4 analyzes the developed FLC and section 5 displays the simulated results. Specific conclusions are summarized in Section 6 before reference list and appendix.

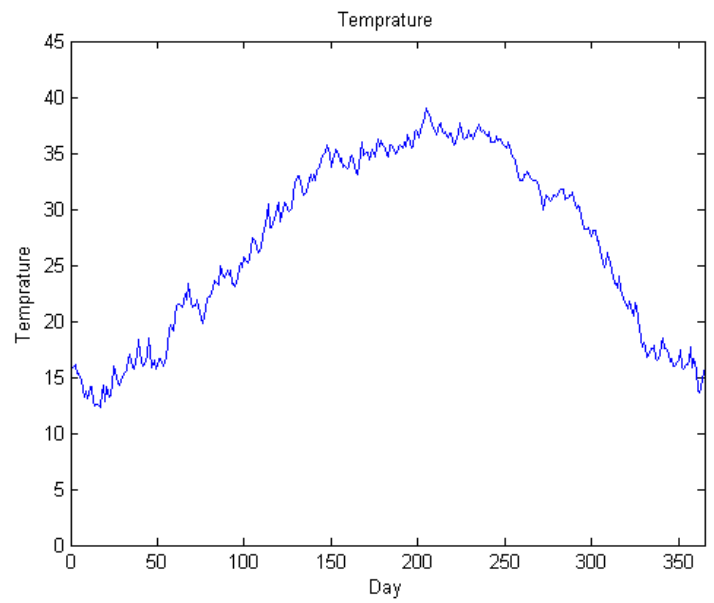

Fig. 1: Average daily temperature $\left({ }^{\circ} \mathrm{C}\right)$ in Kuwait, each day averaged over 6 years.

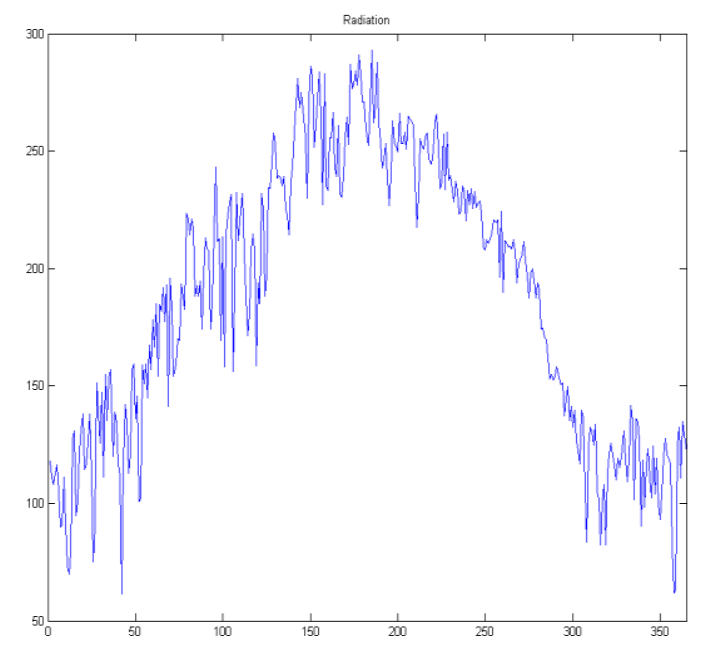

Fig. 2: Average daily solar radiation $\left(\mathrm{W} / \mathrm{m}^{2}\right)$ in Kuwait, each day averaged over 6 years.

\section{Grid Connected PV Systems}

The studied grid-connected PV array has $100 \mathrm{~kW}$ capacity corresponding to $300 \mathrm{~m}^{2}$ roof area of the average house in Kuwait [10]. The array is connected to the grid by means of $250 \mathrm{~V} / 11 \mathrm{kV}$ coupling transformer according to the technical standard of the distribution network in Kuwait. Fig. 3 shows the main components of the PV system, which consists of the solar array, DC/DC boost converter, DC link. The main function of DC/DC boost converter is to adapt the generated voltage of the PV panel to a suitable level corresponding to the MPP [11].

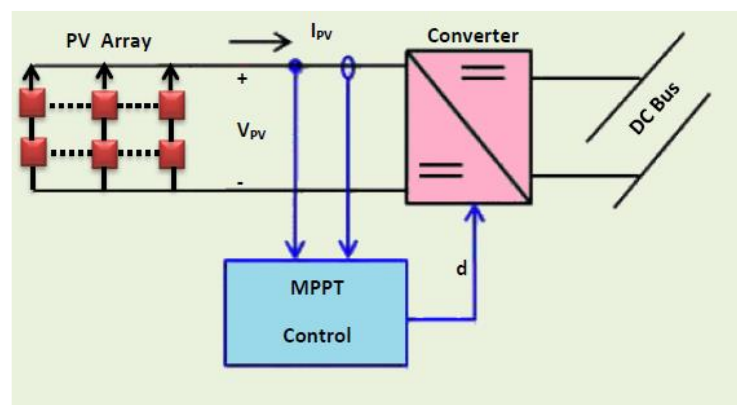

Fig. 3: Components of PV array with maximum power point tracking.

A. Photo-Voltaic Solar Array:

Generally, PV cells are grouped together in similar modules which are interconnected either in series or parallel to form the final PV array. The I-V relation of PV array can be mathematically given by $[2,3]$ :

$$
I=N_{\mathrm{p}} I_{\mathrm{ph}}-N_{\mathrm{p}} I_{\mathrm{o}}\left[\exp ^{\frac{\mathrm{qV}}{\mathrm{AKT} \mathrm{N}}}-1\right]
$$

Where,

q: electron charge.

A: P-N junction ideality factor

$\mathrm{K}$ : Boltzmann constant.

I: Array output current.

Iph: photocurrent as function of irradiation level and junction temperature

$\mathrm{I}_{0}$ : reverse saturation current of diode.

$\mathrm{T}$ : reference cell operating temperature.

$\mathrm{V}$ : Array output voltage.

The array output power is determined through multiplying equation (1) by array voltage and efficiency $\eta$.

\section{B. Boost Converter}

Fig. 4 displays boost converter as a power device with an output DC voltage greater than its DC input [14].

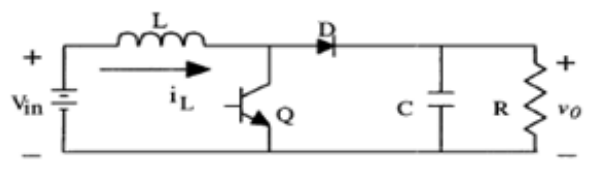

Fig. 4: DC-DC Boost Converter [14]

\section{MPPT Algorithms}

The most widely MPPT techniques available in the literature [4-11] can be summarized as:

\section{A. Perturb and Observe $(P \& O)$ Method}

In this method the operating voltage of the PV array is perturbed by a small increment, and the resulting change of power, $\Delta \mathrm{P}$, is observed [4-8]. If the $\Delta \mathrm{P}$ is positive, then the voltage perturbation is moving toward the MPP. This means that further perturbations in the same direction of voltage change will direct the operating point toward the MPP. If the $\triangle \mathrm{P}$ is negative, the operating point has moved 
away from the MPP, and the direction of perturbation should be reversed to return back toward the MPP. The mathematical formulation of $\mathrm{P} \& \mathrm{O}$ algorithm has 4 cases as follows:

- When $\Delta \mathrm{P}<0 \& \mathrm{~V}(\mathrm{j})>\mathrm{V}(\mathrm{j}-1)$, then $\mathrm{V}(\mathrm{j}+1)=\mathrm{V}(\mathrm{j})-\Delta \mathrm{V}$

- When $\Delta P<0 \& V(j)<V(j-1)$, then $V(j+1)=V(j)+\Delta V$

- When $\Delta P>0 \& V(j)<V(j-1)$, then $V(j+1)=V(j)-\Delta V$

- When $\Delta \mathrm{P}>0$ \& $\mathrm{V}(\mathrm{j})<\mathrm{V}(\mathrm{j}-1)$, then $\mathrm{V}(\mathrm{j}+1)=\mathrm{V}(\mathrm{j})+\Delta \mathrm{V}$

The error signal (e) driving the MPP controller is equal to the differences between the above determined voltage $\mathrm{V}(\mathrm{j}+1)$ and the actual voltage (Vact) of the array.

\section{B. Incremental Conductance Methods}

The incremental conductance [7,8] method (IC) is based on the fact that the derivative of the output power Ppv with respect to the array voltage $\mathrm{Vpv}$ is equal to zero at MPP. The PV array characteristic shows that this derivative is positive to the left of the maximum power point and negative to the right of maximum power point [4,9]. This leads to the following set of equations:

$$
\begin{array}{lr}
\frac{d I_{p v}}{d V_{p v}}=-\frac{I_{p v}}{V_{p v}} & \text { at MPP } \\
\frac{d I_{p v}}{d V_{p v}}>-\frac{I_{p v}}{V_{p v}} & \text { to the left of MPP } \\
\frac{d I_{p v}}{d V_{p v}}<-\frac{I_{p v}}{V_{p v}} & \text { to the right of MPP }
\end{array}
$$

Once MPP has been reached, the operation of PV array is maintained at this point and the perturbation stopped unless a change in $\mathrm{dV}_{\mathrm{PV}}$ is noted. The IC method offers good performance under rapidly changing atmospheric conditions. The converter duty cycle (d) is determined to correct the error (e) given by equation (5).

$$
e=\frac{I}{V}+\frac{d I}{d V}
$$

\section{Fuzzy Logic Controller}

FLC consists of three main parts [7-9, 12,13] as in Fig. A.1 displayed in the Appendix at the end of the paper.

\section{A• Fuzzification}

The fuzzification is the process of converting the system actual inputs values error (e) and change of error (ce) into fuzzy membership function. The inputs e and ce are expressed in terms of seven membership functions (such as ZE (zero), PB (positive big), PM (positive medium), PS (positive small), NB (negative big), NM (negative medium) NS (negative small), as shown in Fig. 5.

\section{$B \cdot$ Rule base \& inference engine}

Fuzzy rule base is a collection of if-then rules that contain all information for defining the controlled parameters. It includes 49 fuzzy control rules listed in Table (I). Fuzzy inference engine is an operating method that formulates a logical decision based on the fuzzy rule setting and transforms the fuzzy rule base into fuzzy linguistic output. In this study Mamdani's fuzzy inference method, with Max-Min operation of fuzzy combination has been used. For example, if e is NB and ce is ZO then the duty cycle D is $\mathrm{PB}$ and so on.

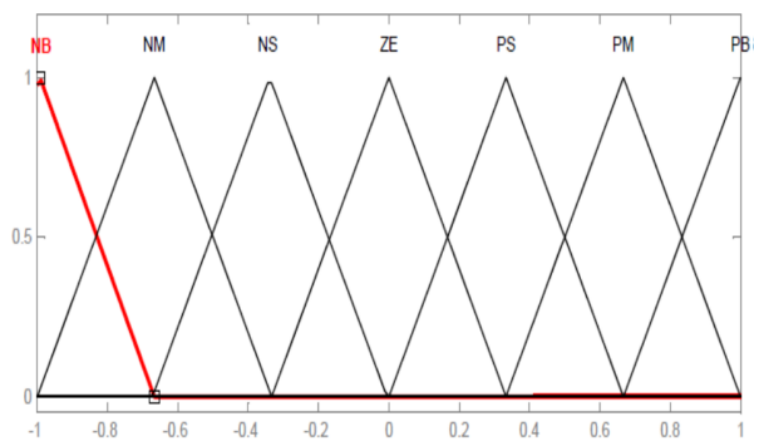

Fig. 5: Graphical view of the normalized membership function

\section{- Defuzzification}

It should be noted that, the output of fuzzy controller is a fuzzy subset. As the DC/DC converter control requires a non-fuzzy value of duty cycle, defuzzication is required. This means, defuzzification converts the inferred fuzzy control action into a numerical value at the output by forming the union of the outputs resulting from each rule. The center of area (COA) algorithm is used for defuzzification of output duty cycle. The control structure of the PV system is displayed in Fig. A.2 of the Appendix.

It should be noted that the values of e and ce will be normalized before treated by the FLC, and the output of FLC will be de-normalized before sent to the booster. The normalized input and output variable are divided into seven membership functions of Fig. 5.

Table 1 Decision rules for the implemented fuzzy system

\begin{tabular}{|c|c|c|c|c|c|c|c|}
\hline CE & NB & NM & NS & ZE & PS & PM & PB \\
\hline NB & ZE & ZE & ZE & NB & NB & NB & NB \\
\hline NM & ZE & ZE & ZE & NM & NM & NM & NM \\
\hline NS & NS & ZE & ZE & NS & NS & NS & NS \\
\hline ZE & NM & NS & ZE & ZE & ZE & PS & PM \\
\hline PS & PM & PS & PS & PS & ZE & ZE & ZE \\
\hline PM & PM & PM & PM & ZE & ZE & ZE & ZE \\
\hline PB & PB & PB & PB & ZE & ZE & ZE & ZE \\
\hline
\end{tabular}




\section{Specification of the Studied System}

Simulink software is used to model the studied gridconnected PV array with a MPPT boost converter as shown in Fig 3. The PV block simulates the nonlinear V-I characteristics of the array at different solar radiations and temperatures. The specifications of studied solar panel are given in Table II.

Table II. PV Panel Specifications

\begin{tabular}{|l|c|r|c|}
\hline Description & Symbol & \multicolumn{1}{|c|}{ Value } & Unit \\
\hline O. C. Voltage & $\mathrm{V}_{\mathrm{OC}}$ & 20.8 & $\mathrm{~V}$ \\
\hline S. C. Current & $\mathrm{I}_{\mathrm{SC}}$ & 3.6 & $\mathrm{~A}$ \\
\hline $\begin{array}{l}\text { O.C.Volt/Temp. } \\
\text { Coefficient }\end{array}$ & $\mathrm{K}_{\mathrm{V}}$ & $-75 \times 10^{-3}$ & $\mathrm{~V} /{ }^{\circ} \mathrm{C}$ \\
\hline $\begin{array}{l}\text { No. of Series } \\
\text { cell/module }\end{array}$ & $\mathrm{N}_{\mathrm{S}}$ & 36 & \\
\hline $\begin{array}{l}\text { No. of series } \\
\text { module }\end{array}$ & $\mathrm{N}_{\mathrm{SS}}$ & 33 & \\
\hline $\begin{array}{l}\text { No. parallel } \\
\text { module }\end{array}$ & $\mathrm{N}_{\mathrm{P}}$ & 60 & \\
\hline $\begin{array}{l}\text { Array power } \\
\text { rating at NOTC }\end{array}$ & $\mathrm{P}_{\mathrm{A}}$ & 100 & $\mathrm{~kW}$ \\
\hline
\end{tabular}

In order to verify the MPP tracker for the studied PV system, the FLC and PID controller are compared under different weather conditions in Kuwait to show how they can effectively and accurately track the MPP. The simulation is carried out using MATLAB/SIMULINK.

Table III shows the parameters of the DC-DC boost converter. The test data consist of hourly SR and temperature for time horizon of 6 years in Kuwait. This data are applied to check the effectiveness of the described MPPT techniques in producing the maximum annual energy of the photovoltaic systems.

Table III. - Buck-Boost Converter Parameters

\begin{tabular}{|l|l|}
\hline Inductance $\mathrm{L}$ & $5 \mathrm{mH}$ \\
\hline Capacitance $\mathrm{C} 1$ & $100 \mu \mathrm{F}$ \\
\hline Capacitance $\mathrm{C} 2$ & $6000 \mu \mathrm{F}$ \\
\hline Frequency & $5 \mathrm{KHz}$ \\
\hline
\end{tabular}

\section{Simulation and Numerical Results}

For each MPPT technique and for hourly input data, the energy supplied by the PV system was calculated for each month averaged over the studied period of 6 years. The implemented controller for the MPPT algorithms is PI type with $\mathrm{Kp}=2$ and $\mathrm{Ki}=0.05$. The same Boost converters with its PWM MPP are used for fair comparison between PI and FLC controller. The results are summarized in Table IV.

The simulation results indicated that the generated energy from the tracking algorithm using fuzzy-IC based MPPT is maximum with annual energy of $169723.6 \mathrm{kWh}$. From the result in Table IV, It can be noted that fuzzy-IC based MPPT and fuzzy-P\&O based MPPT algorithms over the year are superior to both PI-based MPPT algorithms. The produced energy using PI-IC based PPT technique is the lowest of the four studied MPPT methods with annual value of $168711.1 \mathrm{kWh}$. This is attributed to the fact, that the fuzzy-based techniques are more effective to handle non-linear function with fast response.

However, in January the generated energy using the Fuzzy-based P\&O MPP technique is slightly greater than that of the corresponding energy using Fuzzy-base IC MPP techniques. On the other hand, the generated energy is equal by using the two fuzzy-based techniques in February. During the rest of the year, the generated energy using fuzzy-based IC MPP technique is greater compared to the other MPP techniques.

Moreover, for these techniques the choice of sampling period is very critical; if the period is too short, energy production will be very low because of the increased number of electronic switching. If the period is too long, on the other hand, the MPP cannot be closely followed when rapid irradiance variation occurs.

The purposes of the next tests are to investigate the dynamic characteristics of a PV system using the described MPPT controllers. It should be noted that the generated power follows the same shape of the solar insulation inputs. The only difference is a small transient due to rapid insulation variation by using $\mathrm{P} \& \mathrm{O}$ and IC techniques. Comparing the output array voltage, it can be observed that the FLC-based techniques are more stable with solar insulation and temperature variations.

Table IV. - Energy Generated Using MPP Techniques in kWh

\begin{tabular}{|l|l|l|l|l|}
\hline PI-P\&O & PI-IC & FZ-P\&O & FZ-IC & Month \\
\hline 6398.028 & 6395.114 & 6555.302 & 6526.342 & $\mathrm{~J}$ \\
\hline 8271.978 & 8237.94 & 7700.195 & 7700.195 & $\mathrm{~F}$ \\
\hline 13031.28 & 13019.32 & 13463.92 & 13494.81 & $\mathrm{M}$ \\
\hline 15006.48 & 14960.48 & 15200.89 & 15250.44 & $\mathrm{~A}$ \\
\hline 19533.1 & 19489.33 & 19549.42 & 19566.48 & $\mathrm{M}$ \\
\hline 21457.95 & 21472.4 & 21343.67 & 21367.35 & $\mathrm{~J}$ \\
\hline 21385.78 & 21399.92 & 21278.02 & 20679.84 & $\mathrm{~J}$ \\
\hline 20234.44 & 20183.91 & 20532.78 & 20607.69 & $\mathrm{~A}$ \\
\hline 17180.45 & 17129.73 & 17211.37 & 17551.43 & $\mathrm{~S}$ \\
\hline 12153.3 & 12120.26 & 11955.41 & 12380.94 & $\mathrm{O}$ \\
\hline 7680.622 & 7678.018 & 7700.195 & 7838.883 & $\mathrm{~N}$ \\
\hline 6629.102 & 6624.7 & 6750.944 & 6759.182 & $\mathrm{D}$ \\
\hline 168962.5 & 168711.1 & 169242.1 & 169723.6 & Sum \\
\hline
\end{tabular}

In particular due to lack of space, Figs. 6-11 show the selected cases of the PV array voltage response using the 
described MPP algorithms. In the first test, the MPPT controllers are tested under a sunny day, then cloudy day. Figs. 6, 7 display the solar radiation and temperature for sunny and cloudy test days. The dynamic response of the array voltage for sunny day using both PI and FLC controller are compared in Figs. 8, 9. For maximum value of the DC output voltage of $510 \mathrm{~V}$ the peak to peak voltage oscillations reach 23 and $42 \mathrm{~V}$ for the PI-based $\mathrm{P} \& \mathrm{O}$ and PI-based IC technique, respectively. On the other side, the corresponding FLC-based techniques
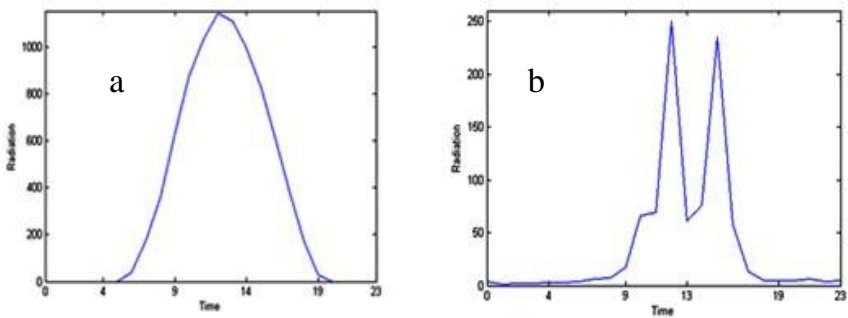

Fig. 6: Solar radiation in $\mathrm{W} / \mathrm{m}^{2}$ (a) sunny and (b) cloudy day
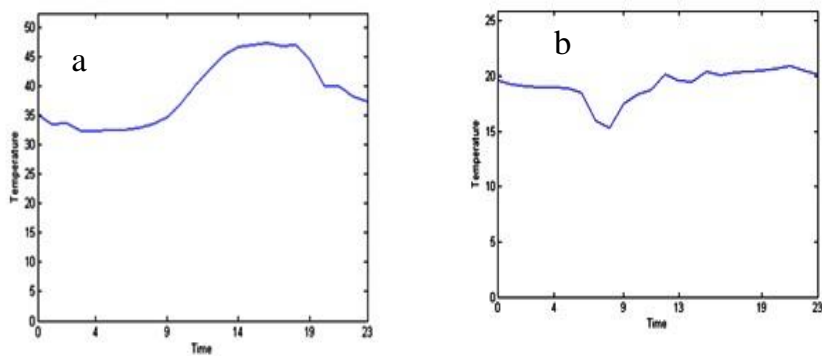

Fig. 7: Temperature ${ }^{\circ} \mathrm{C}$ for (a) sunny and (b) cloudy day
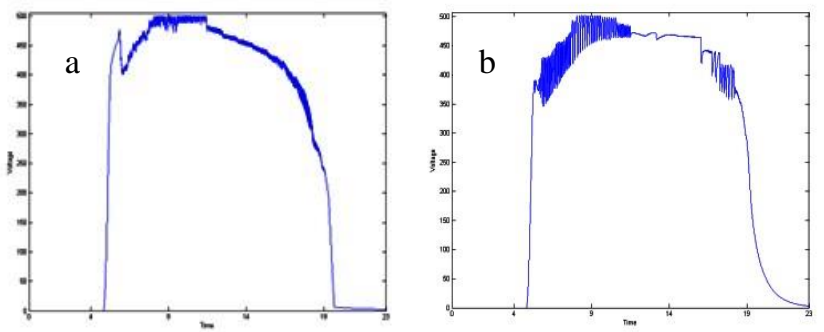

Fig. 8: Dynamic Response of Array voltage using (a) PI-based P\&O (b) PI-basedIC algorithm (sunny day)
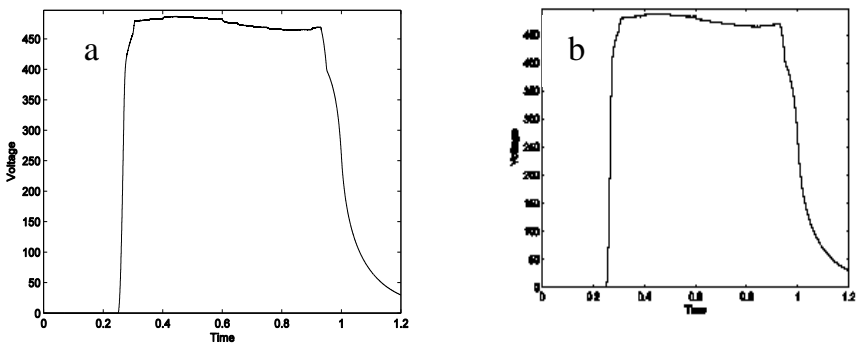

Fig. 9: Response of Array voltage using Dynamic (a) FLC-based P\&O (b) FLC-based IC algorithm (sunny day) deliver the more stable voltage waveforms with negligible oscillation amplitudes. For a cloudy day, Figs. 10, 11 display the voltage response of the PV array using the different MPPT techniques. The maximum voltage oscillations reach 49 to $99 \mathrm{~V}$ using PI-P\&O and PI-IC, respectively. Using FLC-based technique, the corresponding maximum voltage oscillation is less than $20 \mathrm{~V}$. This is attributed to the effectiveness of the fuzzybased techniques to operate the array.
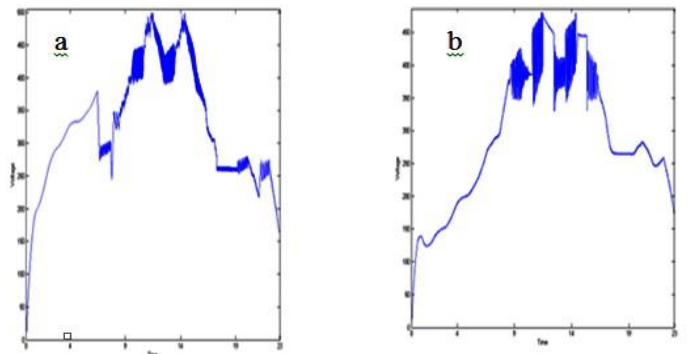

Fig. 10: Dynamic Response of Array voltage using (a) PI-based P\&O (b) PI-based IC algorithm (cloudy day)
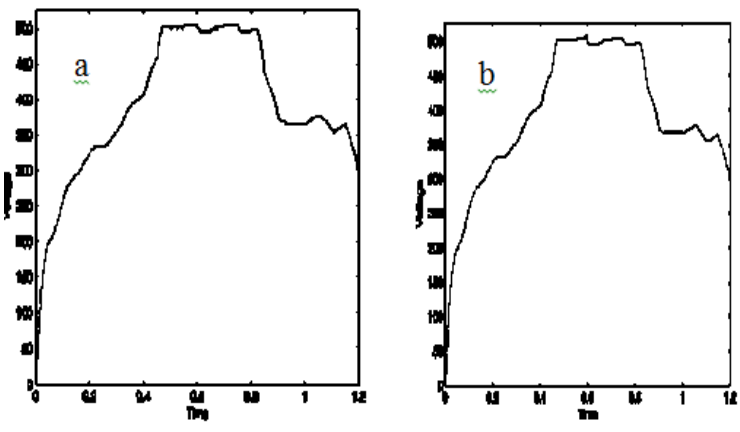

Fig. 11: Dynamic Response of Array voltage using (a) FLC-based P\&O (b) FLC-based IC algorithm (cloudy day)

\section{Conclusions}

This paper presents in details comparative study between PI-based P\&O and IC technique and the corresponding fuzzy-based algorithms for MPPT. To carry out this study the hourly solar radiation, and temperature were collected for a period of 6 years in Kuwait. The Boost converter with the associated PI and fuzzy controller is modeled for this comparison.

Matlab/ simulink have been used for modeling and simulation of the PV array. The capacity of the simulated $\mathrm{PV}$ array is $100 \mathrm{~kW}$ under $1000 \mathrm{~W} / \mathrm{m}^{2}$ and $25^{\circ} \mathrm{C}$ conditions. A ranking was proposed of the different MPPT techniques based on the sum of the energy generated under different weather conditions. Due to lack of space the average generated energy each month was displayed and compared.

The proposed fuzzy logic based control scheme takes the signal of the error e and error change ec as 2 inputs and computes the duty cycle of the boost converter as an 
output to adjust the DC/DC boost converter for the MPP. The controller was implemented on a $100-\mathrm{kW}$ prototype PV system. Simulation results show clearly that the performance of the FLC based MPPT is superior compared to the conventional PI-based control technique.

The results indicated that the fuzzy-based algorithm is in general more efficient than PI-based MPPT technique. The fuzzy-based IC technique provides the greatest annual energy supply for the studied period of 6 years. This is confirmed by their widespread use of FLC in paractical implementation in many control systems. The generated power output of all tested techniques has the same shape as the solar insulation.

In addition, the dynamic response comparison of output voltage has been traced under different condition of available radiation and temperature. The MPPT controller was tested under a sunny day, and then cloudy and partially cloudy days to calculate the amount of the oscillation in PV operating points. The simulation results indicated that the fuzzy-based techniques delivered more stable voltage and current signal of the PV array compared to PI-based techniques.

\section{Acknowledgement}

The authors acknowledge the funding of the Kuwait Foundation for Advancement of Science (KFAS) and the Kuwait-MIT Centre for Natural Resources and Environment (CNRE)

\section{References}

[1] Ministry of Electricity and Water, "Statistical year book: Electrical Energy" 36 th Ed. State of Kuwait, 2011.

[4] M. El-Sayed, S. Leeb, "Evaluation of maximum power point tracking algorithms for photovoltaic electricity generation in Kuwait", Renewable Energy and Power Quality Journal (RE\&PQJ) ISSN 2172-038X, No. 12, April 2014.

[2] Photovoltaic devices - part 3: Measurement principles for terrestrial Photovoltaic (PV) solar devices with reference spectral irradiance data, IEC 60904-3-ED. 2.0, 2008.

[3] T. Nordmann and L. Clavadetscher, "Understanding tempreture effect on pv system performance", Proceedings of 3rd World Conference on Photovoltaic Energy Conversions, vol. 3, May 2003, pp. 2243-2246.

[5] T. Esram and P. Chapman, "Comparison of Photovoltaic array maximum power point tracking techniques," IEEE Transactions on Energy Conversion, Vol. 22, no. 2, Jun. 2007, pp. 439-449.

[6] T. L. Nguyen and K.-S. Low, "A global maximum power point tracking scheme employing direct search algorithm for Photovoltaic systems," IEEE transactions on Industrial Electronics, vol. 57, no. 10, Oct. 2010, pp. 3456-3467.

[7] Chokri Ben Salah, Mohamed Ouali, "Comparison of Fuzzy Logic and Neural Network in Maximum Power Point Tracker for PV Systems", Elsevier, Electric Power Systems Research, vol.81, pp.43-50, July 2011.
[8] Mohamed Salhi1 ,Rachid El-Bachtri2, "Maximum Power Point Tracker Using Fuzzy Control for Photovoltaic System", International Journal of Research and Reviews in Electrical and Computer Engineering, vol.1, no.2, pp.69-75, June 2011.

[9] Alireza Rezaei and S.Asghar Gholamian" Maximum Power Point Tracking of Solarex MSX PV Module System using FLC, International Journal on Computational Sciences \& Applications (IJCSA) Vo2, No.5, October 2012.

[10] A. Mumin, A.Al-Mohaisen, "Greening the Kuwaiti Houses: Studying the Potential of Photovoltaics for Reducing the Electricity Consumption", Global Built Environment Review GBER Journal, Vol. 5 No. 3, pp. 3 10,2006

[11] Trishan Esram , Pa trick L. Chapman, "Comparison of photovoltaic array maximum power point tracking techniques", IEEE Transactions on energy conversion, Vol. 22, No. 2, June 2007

[12] Ansari, M. F., Chatterji, S., \& Iqbal, A. (2011). Fuzzy logic-based MPPT controllers for three-phase gridconnected inverters. International Journal of Sustainable Energy, pp. 1-10, (2011).

[13] M. Karakose, E. Akin., " Block-based fuzzy controllers", IJRRAS, International Journal of Research \&Reviews in Applied Sciences , 3 (1), pp. 100-110, April (2011).

[14] J-H. Su, J.-J. Chen, D.-S. Wu, Learning Feedback Controller Design of Switching Converters Via MATLAB/SIMULINK, IEEE Transactions on Education, vol. 45, November 2002.

\section{Appendix}

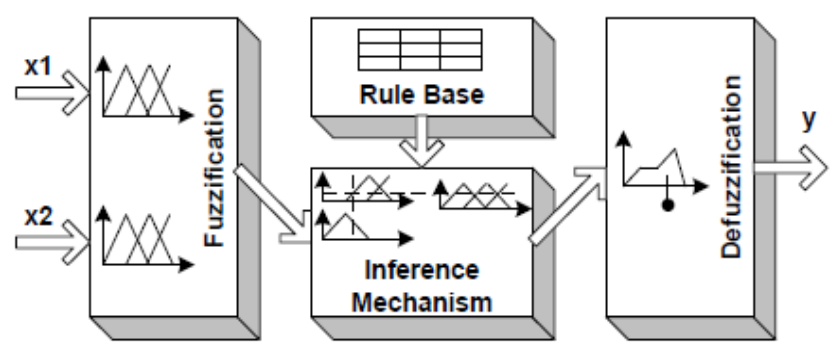

Fig. A.1: Structure of a fuzzy controller [13] x1=error (e) \& x2 =de/dt (ce)

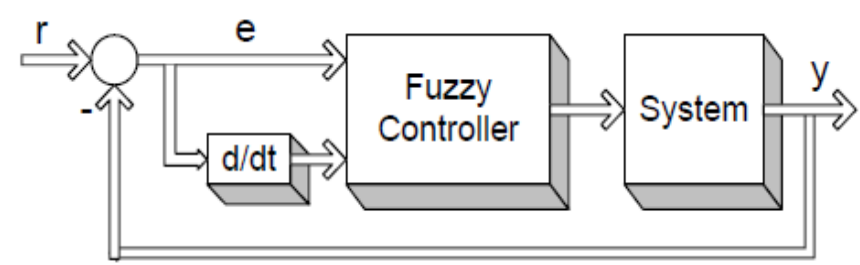

Fig. A.2: Control system structure with a fuzzy Controller [13] 